\title{
Avaliação da transparência das informações sobre políticas de apoio aos produtores rurais no Brasil
}

Wellington Pinheiro de Araujo e Mauro Eduardo Del Grossi

\section{Introdução}

O envolvimento dos cidadãos no controle social das políticas públicas depende da transparência com que o governo divulga seus atos. O conceito de transparência tem evoluído nos últimos anos da simples divulgação de dados para a cobrança de uma atitude proativa dos agentes que representam o Estado, ao fornecer informações, em qualidade e quantidade, que estimulem e possibilitem o controle social (MATIAS-PEREIRA, 2010). Neste artigo, buscou-se ressaltar o debate sobre os principais aspectos que a teoria tem abordado sobre a forma de comunicação do Estado, com foco na transparência da divulgação de informações governamentais das políticas de apoio aos produtores rurais.

As políticas de apoio aos produtores rurais abrangem instrumentos de política macroeconômica e microeconômica, dentre os quais cabe destacar: transferências diretas ao produtor, concessão de crédito subsidiado, garantia de renda e perdão de dívidas (OCDE, 2005).

Tais políticas são sustentadas pela sociedade de maneira direta, por meio de recursos orçamentários públicos, ou de maneira indireta, na forma de oferta de 
financiamentos ou reescalonamento de dívidas com encargos inferiores aos de mercado. Desse modo, é lícito questionar se o poder público, gestor dos programas de apoio aos agricultores, adota um modelo de divulgação de dados que permite ao cidadão brasileiro ter clareza sobre o volume de recursos que estão sendo direcionados a esse setor específico.

O objetivo deste artigo foi avaliar o nível atual de transparência das informações sobre políticas de apoio aos produtores rurais no Brasil, verificando se os dados sobre os benefícios concedidos são apresentados de maneira que permitam um amplo acesso dos cidadãos que desejam entender, participar e monitorar a utilização de recursos aplicados nessas políticas públicas.

A hipótese que norteou a pesquisa é a de que uma parte significativa dos dados sobre políticas de apoio aos produtores rurais não é publicada pelos agentes públicos responsáveis, ou é apresentada de maneira complexa e pouco interativa, dificultando o efetivo acesso dos cidadãos a essas informações.

\section{Transparência na gestão pública}

Nos últimos anos, ganhou força a percepção de que o sucesso dos governos na implementação de políticas públicas depende cada vez mais de uma postura dinâmica e proativa por parte dos gestores públicos, acompanhada de maior envolvimento da sociedade nas ações do governo. Diversos autores atribuem à participação social uma maior justiça no atendimento das demandas, redução da corrupção e melhoria da eficiência do Estado (Matias-Pereira, 2002; STIGLITZ, 2002; JARDiM, 1999).

A transparência na disponibilização de informação pelo setor público contribui para o combate à corrupção e propicia o aperfeiçoamento constante das ações estatais. Com o aumento da transparência, os mecanismos de controle social são aprimorados, com impactos positivos sobre a responsabilização dos governantes. Transparência, nesse sentido, é mais do que "a obrigação de informar", deve ser impulsionada pelo "desejo de informar", sabendo que dessa boa comunicação resulta um clima de confiança tanto internamente quanto nas relações com terceiros (Matias-Pereira, 2010).

O conceito de transparência é mais abrangente, portanto, do que a simples oferta de dados e informações de maneira bruta. A transparência administrativa deve atender ao conceito de comunicação, que envolve o estabelecimento de uma relação de troca com o cidadão. Com isso, a administração volta-se para a sociedade, tendo que adaptar sua linguagem, no sentido de se tornar o mais amplamente compreensível, já que a informação só é eficaz se o cidadão acessa e interpreta corretamente a mensagem (JARDIM, 1999).

Desde o fim do período de autoritarismo, em meados dos anos 1980, a prática da democracia no Brasil tem-se caracterizado, entre outros aspectos, pela demanda da sociedade por mais ética e transparência na condução dos negócios públicos. Diversos autores, porém, têm apontado a presença de dificuldades para que o relacionamento entre sociedade e governo no Brasil siga os padrões de transparência observados em outros países, em função da cultura burocrática e da fragmentação de informações (Jardim, 1999; Matias-Pereira, 2002; TORRES, 2004; ForTIS, 2008).

A política de divulgação de informações do Governo Federal tem priorizado a área de administração de dados com elevado uso de recursos tecnológicos, incluindo-se a internet como fator de 
transparência governamental. Esse sistema de informações, entretanto, não se encontra devidamente integrado, de forma que possa oferecer ao cidadão as informações que permitam visualizar com clareza todas as ações governamentais. Ainda não se atingiu, desse modo, o nível de transparência que forneça informações completas, objetivas, confiáveis, relevantes e de fácil acesso e compreensão (Matias-Pereira, 2002).

As informações sobre políticas de apoio aos produtores rurais, por exemplo, estão fragmentadas em documentos e bancos de dados geridos por inúmeras entidades, cabendo destacar: Ministério da Agricultura, Pecuária e Abastecimento (Mapa); Ministério do Desenvolvimento Agrário (MDA); Secretaria do Tesouro Nacional do Ministério da Fazenda (STN/MF); Companhia Nacional de Abastecimento (Conab); Banco Central do Brasil (BCB); e Banco Nacional de Desenvolvimento Econômico e Social (BNDES). Cada uma dessas instituições tem uma política de divulgação de dados distinta, o que dificulta a coleta e a estruturação de informações gerenciais, essenciais a uma análise global da participação do setor público no fomento à atividade agropecuária.

Os debates teóricos sobre as políticas de transparência encontram-se relacionados a um mecanismo experimentado no mundo anglo-saxão e escandinavo, denominado accountability (CARLOS et al., 2008). Esse é um termo sem tradução para o português, que enfatiza a importância de adoção de mecanismos de controle, responsabilização e transparência administrativa.

O conceito de accountability, aplicado à administração pública, envolve um conjunto de mecanismos e procedimentos que levam os decisores governamentais a prestar contas dos resultados de suas ações de maneira proativa, informando e justificando seus planos e ações, o que proporciona maior transparência e exposição pública das políticas públicas. Nesse sentido, espera-se que os agentes públicos divulguem informações à sociedade por iniciativa própria, de forma espontânea, independente de qualquer solicitação (ACKERMAN, 2005; JARDIM, 1999; Matias-Pereira, 2008).

A accountability serve de referencial para a avaliação do nível de transparência dos gastos públicos com políticas de apoio aos

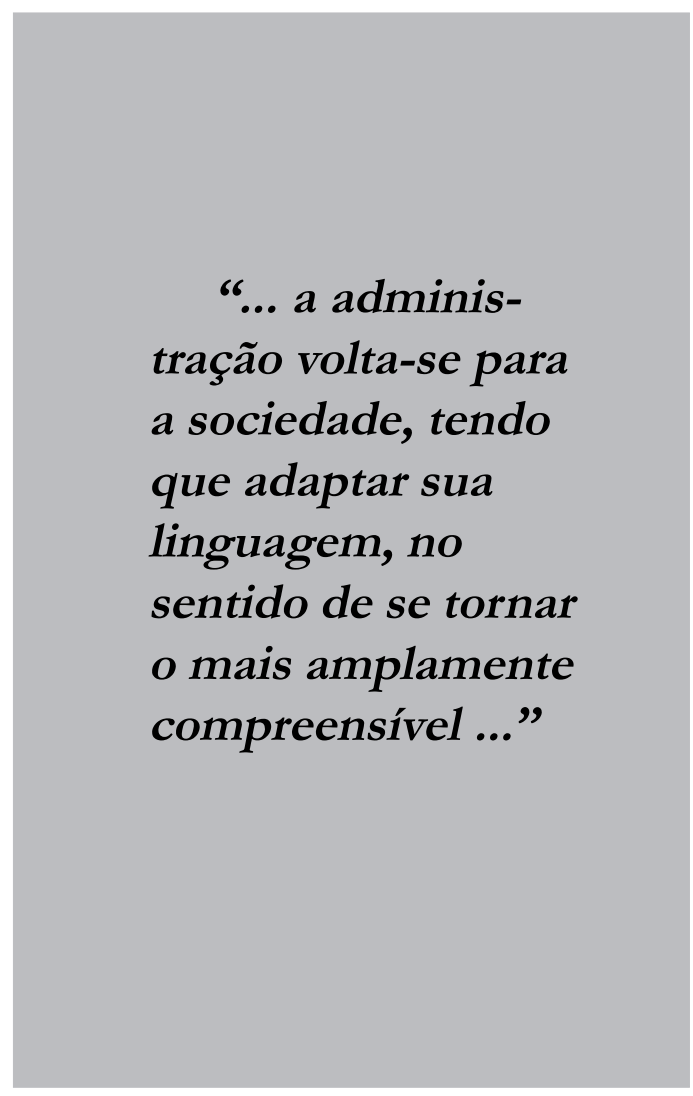

produtores rurais. A concessão de subsídios à produção agropecuária constitui importante política governamental e, como tal, deve ser objeto de um processo de transparência que não se resuma à oferta de dados e informações. Para que o fluxo de comunicação complete seu ciclo, é necessário que o destinatário acesse, compreenda os dados e tenha a capacidade de 
utilizá-los como insumo para a tomada de decisões.

A ideia do exercício de um controle direto das políticas públicas pela sociedade decorre da constatação de que os sistemas de representação eleitorais são insuficientes para garantir as melhores escolhas para o atendimento das demandas sociais, sendo necessário introduzir controles e sanções contínuas sobre os representantes (LAVALLE e VERA, 2011). Em termos ideais, esse controle deveria ser exercido pelos cidadãos diretamente, mas, em geral, as reivindicações individuais não têm força suficiente para impor limites à atuação governamental (CAmpos, 1990).

O desgaste da legitimidade das instituições tradicionais de representação favorece espaços de participação de outras organizações que compõem a sociedade civil (Avritzer, 2007). Esse contexto fortalece o papel da accountability societal, que consiste no controle e responsabilização dos agentes públicos por instituições públicas, mas de caráter não estatal (FILGUEIRAs, 2011), tais como conselhos gestores, associações, movimentos, organizações não governamentais, entidades assistenciais, cooperativas etc.

Quando o controle social é exercido por atores coletivos organizados, e não por cidadãos, surgem novas modalidades de representação com lógicas próprias de funcionamento (Lavalle, 2008). Essas novas formas de exercício da cidadania despertam questões sobre o uso das informações por tais instituições. Neste trabalho, não foi possível maior aprofundamento nessa questão, já que se centrou na abordagem de aspectos relacionados à qualidade e disponibilidade dos dados. Sugere-se, para pesquisas futuras, uma análise mais apurada em como os vários atores sociais, organizados ou não, fazem uso dessas informações.

\section{Seleção dos dados para apura- ção da transparência das políticas de apoio aos produtores rurais}

Nesta pesquisa, foram selecionadas para análise as políticas de apoio aos produtores rurais elaboradas e executadas pelo Governo Federal, uma vez que os gastos dessa esfera correspondem a cerca de $75 \%$ do total efetuado pelos diferentes níveis de governo (Gasques, Villa Verde e Bastos, 2006). Além disso, os modelos adotados pelo Poder Executivo federal têm maiores condições de moldar e influenciar as políticas públicas a serem adotadas pelos Estados e Municípios para esse setor econômico.

Como são numerosas as políticas de apoio adotadas pelo Governo Federal e várias as fontes de recursos utilizadas na sua implementação, fez-se necessário identificar aquelas de maior relevância em termos de volumes de recursos alocados ou transferidos, na forma de benefícios diretos ou indiretos, aos produtores rurais. Nesse sentido, adotou-se, como primeira etapa, a identificação das políticas de apoio aos produtores rurais responsáveis pelas maiores transferências financeiras, a partir de relatórios da Organização para a Cooperação e Desenvolvimento Econômico (OCDE).

$A$ variedade de instrumentos de apoio ao setor agropecuário, não só no Brasil, mas em nível mundial, dificulta a mensuração e comparação dos níveis de subsídios concedidos pelos diferentes governos. Em função disso, a OCDE desenvolveu uma série de indicadores a fim de acompanhar e avaliar a evolução da política agrícola, com o objetivo de estabelecer parâmetros que permitam o diálogo político entre os países, assim como fornecer os dados econômicos para avaliação da eficiência e eficácia das políticas (OCDE, 2010). 
Entre esses indicadores, merece destaque a Estimativa de Apoio ao Produtor, conhecida pela sigla PSE (Producer Support Estimate). O PSE mede os benefícios diretos e indiretos concedidos aos produtores rurais $(\mathrm{OECD}, 2010)$ e é considerado $\mathrm{o}$ indicador mais apropriado para comparar as políticas de apoio adotadas por diferentes países, pelo fato de ser uma medida relativa (e não nominal, em moeda corrente), o que elimina o problema da taxa de câmbio utilizada (RAmos, 2011).

A OCDE define o PSE como:

[...] indicador do valor monetário anual das transferências brutas, implícitas e explícitas, dos consumidores e dos contribuintes para os produtores agrícolas, medidas em nível de propriedade, decorrentes de medidas de política de apoio, qualquer que seja sua natureza, seu objetivo ou efeitos para a renda do produtor (OECD, 2010, p. 17).

Esse indicador é abrangente, sendo composto de pagamentos orçamentários que aparecem nas contas do governo, mas também incluindo outras concessões que não implicam, necessariamente, as despesas orçamentárias. As medidas de apoio incluídas no PSE são classificadas de acordo com critérios de aplicação específica, que identificam as características das medidas de política econômica que são importantes para a análise dos potenciais impactos das políticas de produção, renda, consumo, comércio e meio ambiente (OECD, 2010).

Dado o conceito do PSE antes descrito, adotou-se nesta pesquisa a expressão "políticas de apoio aos produtores rurais" para designar as políticas governamentais que implicam transferências financeiras diretas ou indiretas para o setor rural. Essa terminologia foi considerada mais apropriada do que os termos "subsídio" e "subvenção econômica", designações mais restritas que podem não captar alguns instrumentos adotados pelos governos para apoiar o setor agropecuário.

Os dados da OCDE, de 2008 a 2012, apontam, para o Brasil, um PSE médio da ordem de 4,95\% da receita bruta total dos agricultores (Tabela 1), o que significa que o valor estimado das transferências de políticas que apoiam a agricultura para produtores individuais, provenientes dos consumidores e contribuintes, representa uma média de transferências anuais de cerca de $\mathrm{R} \$ 14,8$ bilhões.

Conforme se verifica na Tabela 1 , as principais políticas de apoio ao produtor, medidas com base no PSE, que se aplicam ao caso do Brasil são: Apoio Baseado na Produção de "Commodities", representando no período de 2008 a 2012, em média, 52,8\% do PSE; e os Pagamentos Baseados no Uso de Insumos, com média de $45,3 \%$ do PSE, no mesmo período.

A política de apoio baseada na produção consiste em ações governamentais voltadas a viabilizar a comercialização da produção agropecuária. Para o atendimento dessa finalidade, as principais medidas de apoio vigentes no período de 2008 a 2012 consistem em gastos orçamentários para formação de estoques públicos, por meio das Aquisições do Governo Federal (AGF), e para garantia e sustentação de preços na comercialização de produtos agropecuários, que engloba instrumentos como Prêmio de Escoamento do Produto (PEP), Prêmio Equalizador Pago ao Produtor (Pepro) e Contrato de Opções.

A política de apoio baseada no uso de insumos, por sua vez, abrange a concessão de crédito com encargos financeiros inferiores aos praticados no 
mercado. O Crédito Rural para produtores rurais é uma das principais formas de transferência praticadas no Brasil, por meio do qual são oferecidos recursos para o financiamento do Custeio e Investimento Agropecuário, e também para o Programa Nacional de Agricultura Familiar (Pronaf).

Quando os agricultores podem tomar crédito em termos favoráveis, se comparados a outros segmentos, criam-se transferências que necessitam ser contabilizadas nas estimativas de apoio aos produtores
(OecD, 2010). Cabe lembrar que o indicador da OCDE não se restringe aos desembolsos orçamentários, captando quaisquer tipos de benefícios, como, por exemplo, os créditos subsidiados, mesmo que oriundos de fontes privadas como as exigibilidades bancárias.

Outra forma de transferência, também captada pelo PSE, é o reescalonamento de dívidas rurais. Essa política envolve renegociação de dívidas vencidas a taxas reduzidas e perdão parcial ou total dos débitos.

Tabela 1: Estimativa de Subsídio ao Produtor (PSE) para o Brasil (2008 a 2012)

\begin{tabular}{|c|c|c|c|c|c|c|}
\hline & 2008 & 2009 & 2010 & 2011 & 2012 & Média \\
\hline $\begin{array}{l}\text { I. Receita Bruta Total } \\
\text { dos Agricultores }\end{array}$ & $256.200,98$ & $260.819,12$ & $275.811,42$ & $337.648,79$ & $370.386,68$ & $300.173,40$ \\
\hline $\begin{array}{l}\text { II. Estimativa de } \\
\text { Subsídio ao Produtor } \\
\text { (PSE) }\end{array}$ & $9.826,99$ & $17.250,64$ & $12.670,28$ & $16.711,89$ & $17.578,69$ & $14.807,70$ \\
\hline $\begin{array}{l}\text { A. Apoio Baseado } \\
\text { na produção de } \\
\text { "Commodities" }\end{array}$ & $3.272,82$ & $12.224,76$ & $7.983,93$ & $8.140,08$ & $7.538,86$ & $7.832,09$ \\
\hline $\begin{array}{l}\text { A.1. Sustentação de } \\
\text { preço }\end{array}$ & $2.077,91$ & $11.144,06$ & $7.395,46$ & $7.135,28$ & $6.946,53$ & $6.939,85$ \\
\hline $\begin{array}{l}\text { A2. Pagamento Baseado } \\
\text { na produção }\end{array}$ & $1.194,90$ & $1.080,70$ & 588,47 & $1.004,80$ & 592,33 & 892,24 \\
\hline $\begin{array}{l}\text { B. Pagamentos Baseados } \\
\text { no uso de insumos }\end{array}$ & $6.465,08$ & $4.895,82$ & $4.366,29$ & $8.441,81$ & $9.412,70$ & $6.716,34$ \\
\hline $\begin{array}{l}\text { B1. Uso de Insumos } \\
\text { variáveis }\end{array}$ & $3.172,14$ & $1.800,14$ & $2.048,87$ & $4.761,93$ & $5.945,06$ & $3.545,63$ \\
\hline $\begin{array}{l}\text { B2. Formação de capital } \\
\text { fixo (Investimento) }\end{array}$ & $3.259,79$ & $3.061,61$ & $2.280,31$ & $3.652,46$ & $3.073,21$ & $3.065,48$ \\
\hline $\begin{array}{l}\text { B3. Serviços de Extensão } \\
\text { Rural }\end{array}$ & 33,15 & 34,08 & 37,11 & 27,42 & 394,43 & 105 \\
\hline $\begin{array}{l}\text { C. Pagamento Baseado } \\
\text { na Produção Requerida } \\
\text { Corrente (Garantia - } \\
\text { Safra) }\end{array}$ & 89,10 & 130,06 & 320,06 & 130,00 & 627,13 & 259,27 \\
\hline $\begin{array}{l}\text { PSE - Percentual da } \\
\text { Receita Bruta dos } \\
\text { Agricultores }\end{array}$ & $3,84 \%$ & $6,61 \%$ & $4,59 \%$ & $4,95 \%$ & $4,75 \%$ & $4,95 \%$ \\
\hline
\end{tabular}

Fonte: OCDE. Informações completas disponíveis em: http://www.oecd.org/agriculture/agricultural-policies / producer and consumer support estimatesdatabase.htm. Tradução do autor (as siglas correspondem aos termos originais em inglês). 
Tais concessões também geram transferências e, por isso, são incluídas no cálculo das estimativas de apoio, independentemente dos motivos que provocaram os atrasos no pagamento ou dos objetivos do governo na reestruturação.

Adotando, para os efeitos desta pesquisa, o critério da relevância da informação para o público, a partir do montante de transferências recebidas pelos produtores rurais, selecionou-se para análise as principais políticas captadas pelo PSE, que nos últimos anos foram: Crédito Rural (financiamentos para Custeio, Investimento e Pronaf), políticas de apoio à comercialização (formação de estoques e garantia e sustentação de preços na comercialização de produtos agropecuários) e reescalonamento de dívidas rurais.

Muitos desses programas contam com mais de uma fonte de recursos, cujas informações são publicadas de maneiras diversas. Para analisar a transparência das informações sobre as políticas públicas de apoio aos produtores rurais, é conveniente identificar as fontes que têm maior peso no seu financiamento.

No caso das políticas de crédito rural, utilizou-se como critério de relevância para seleção das fontes o volume médio de crédito concedido no período de 2008 a 2012, a partir dos dados colhidos no Anuário Estatístico do Banco Central. Com relação às políticas de apoio à comercialização, o Tesouro Nacional é a fonte principal dos recursos despendidos na formação de estoques públicos e no programa de garantia e sustentação de preços. Neste caso, foi considerada a média de execução financeira no período de 2008 a 2012.

No caso do reescalonamento de dívidas, as informações disponíveis não permitiram a identificação das fontes específicas afetadas pelos alongamentos e renegociações. Em função disso, optou-se por fazer a análise das fontes de recursos de maneira agregada, por tipo de impacto principal que suportam, quais sejam: subsídios explícitos na Lei Orçamentária Anual e subsídios implícitos nas dívidas rurais securitizadas com títulos do Tesouro Nacional, ambos no período de 2008 a 2012.

Adotando tais critérios de seleção, destacaram-se para análise os instrumentos de

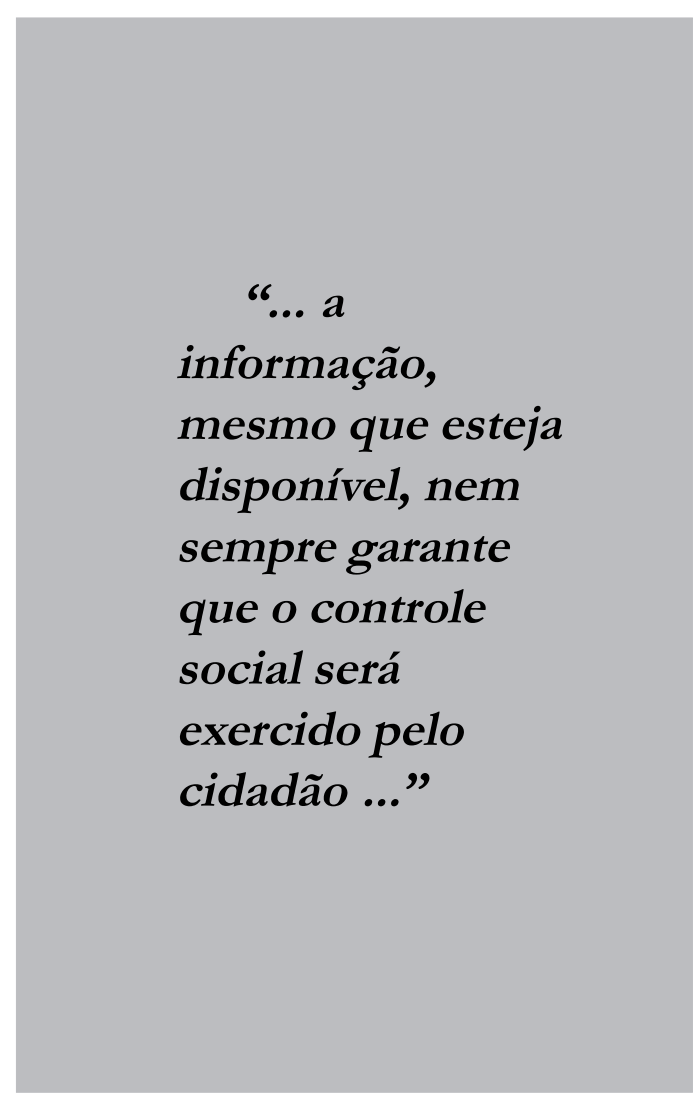

apoio aos produtores rurais e as respectivas fontes constantes do Quadro 1.

\section{Método de Análise}

No intuito de contar com parâmetros mais consistentes para avaliar o nível de transparência das comunicações governamentais, diversas organizações têm 
Quadro 1: Instrumentos de apoio aos produtores rurais e fontes de recursos selecionados para avaliação de transparência

\begin{tabular}{|l|l|}
\hline Instrumento de Apoio ao Produtor Rural & Fontes de Recursos \\
\hline Crédito Rural - Custeio & Recursos Obrigatórios \\
\hline Crédito Rural - Investimento & Fundos Constitucionais e BNDES/Finame \\
\hline Crédito Rural - Pronaf & Poupança Rural \\
\hline Política de Apoio à Comercialização & Tesouro Nacional \\
\hline Reescalonamento de Dívidas & Subsídios Explícitos e Subsídios Implícitos* \\
\hline
\end{tabular}

Fonte: Elaborado pelo autor.

* No Reescalonamento de Dívidas Rurais, foi avaliada de forma agregada a transparência das fontes de recursos, por tipo de subsídio.

trabalhado na elaboração e aplicação de índices e indicadores de transparência.

Para os objetivos desta pesquisa, o trabalho adotado como referência foi o Índice do Orçamento Aberto, gerado a partir da Pesquisa do Orçamento Aberto, no âmbito da Parceria Internacional de Orçamento (International Budget Partnership-IBP). A IBP foi criada em 1997 pelo Centro de Orçamento e Políticas Públicas, uma organização de pesquisa sem fins lucrativos, sediada nos Estados Unidos, que apoia organizações interessadas em fortalecer o processo de orçamento público em seus países (IBP, 2011).

A sistemática da IBP enfoca os documentos orçamentários e seus conteúdos. A Pesquisa de Orçamento Aberto, coordenada pela IBP, analisa a quantidade de informações disponíveis em documentoschave do orçamento que os governos deveriam emitir durante o ciclo orçamentário anual. A pesquisa é desenvolvida com base em questionário, cujas respostas são coletadas por parceiros não governamentais dos países envolvidos. A média das respostas que avalia o acesso público a informações do orçamento é usada para conceder o Índice do Orçamento Aberto de cada país (IBP, 2011).
Com o propósito de agrupar as respostas, são atribuídos escores numéricos de $100 \%, 67 \%$, 33\% e 0 , de acordo com os itens escolhidos (opções a, b, c ou d, respectivamente). As questões com a resposta de letra "e" - não aplicável - não são contabilizadas como parte da categoria agrupada (IBP, 2011). Para mostrar o desempenho de um país no índice, aquele que atinge um escore entre $81 \%$ e $100 \%$ indica que seu "governo disponibiliza uma quantidade importante de informações aos cidadãos". O país com escore de $61 \%$ a $80 \%$ indica que o "governo disponibiliza significativa informação aos cidadãos". O país com escore de $41 \%$ a $60 \%$ indica que o "governo fornece alguma informação aos cidadãos". O país com escore de $21 \%$ a $40 \%$ indica que o "governo disponibiliza informações mínimas aos cidadãos". Finalmente, o país com escore abaixo de $20 \%$ indica que o "governo disponibiliza limitada ou nenhuma informação” (IBP, 2011).

Em 2012, a IBP concluiu uma pesquisa que objetivou levantar o grau de transparência orçamentária de 100 países, classificando-os segundo a quantidade de informações contidas em alguns documentos-chave do orçamento que os governos deveriam publicar durante $\mathrm{o}$ ano. 
O Brasil atingiu 73\% dos pontos possíveis, denotando abertura orçamentária acima da média - "governo disponibiliza significativa informação aos cidadãos" (Iвp, 2012).

Como se pode verificar, a metodologia utilizada pela IBP privilegia a avaliação de transparência de documentos orçamentários, ou seja, não capta a concessão de benefícios a grupos específicos, que não transitem pelo orçamento. Considerando que, nesta pesquisa, se lidou também com várias ações que não transitam pelas leis orçamentárias, utilizou-se apenas a lógica e filosofia da "Pesquisa de Orçamento Aberto" para elaborar quesitos de avaliação e respectivas notas, a fim de contemplar as peculiaridades do universo de documentos que foram objeto de verificação.

Outra divergência entre as metodologias diz respeito ao entendimento do conceito de informação "disponível para o público". A IBP considera como publicamente disponíveis todos os dados que qualquer cidadão possa obter, mesmo que para isso seja necessária solicitação à autoridade pública emissora do documento (Iвp, 2011). Nesta pesquisa, por conta do conceito de accountability, que valoriza a proatividade dos governantes na oferta de dados, adotou-se entendimento diverso, atribuiu-se nota máxima apenas aos documentos produzidos e disponibilizados ao público amplamente e de maneira detalhada.

A metodologia adotada neste trabalho consistiu, portanto, na análise e atribuição de "notas" a quesitos considerados importantes para assegurar a transparência e a acessibilidade das informações sobre as principais políticas de apoio aos produtores rurais. Os quesitos de avaliação priorizaram etapas importantes do ciclo das políticas públicas voltadas ao setor agropecuário, levando ainda em conta as peculiaridades dos instrumentos avaliados.

A seguir, estão relacionados os quesitos de avaliação de transparência, acompanhados dos critérios que orientaram sua adoção.

- Previsão dos benefícios na lei orçamentária anual: a lei orçamentária anual, proposta pelo Poder Executivo e apreciada pelo Poder Legislativo, é considerada pela OCDE como o principal documento voltado à transparência do uso de recursos públicos (OeCD, 2002). Desse modo, qualquer avaliação de transparência de uma política deve verificar a inclusão ou não dos respectivos recursos nessa lei.

- Existência de descritor da ação governamental: ao lançar programas e ações voltados à solução de demandas públicas, o Governo Federal normalmente utiliza denominações que nem sempre expressam de maneira precisa o conteúdo e o alcance daquela política pública. As ações governamentais devem ser estruturadas de modo a facilitar sua compreensão até mesmo por pessoas de limitado conhecimento técnico no campo das finanças públicas (SANCHeS, 2004).

- Acompanhamento da execusão da despesa: o controle social pressupõe acesso aos dados de execução das despesas públicas, para que seja mais eficaz na identificação de fraudes e desvios que possam vir a comprometer o atendimento dos objetivos da política (Matias-Pereira, 2005).

- Levantamento de séries históricas: informações estruturadas e gerenciais de médio e longo prazo contribuem para avaliações de eficiência e eficácia do gasto público (Torres, 2004).

- Identificação dos beneficiários: dada a escassez dos recursos públicos, é fundamental que os cidadãos possam identificar os grupos e setores beneficiados pelas políticas de apoio. 
- Aferição de resultados e do cumprimento de metas: última etapa do ciclo da política pública, a análise dos resultados alcançados produz informação necessária à correção de distorções. A avaliação do gasto pode resultar em alocações mais honestas e inteligentes, redundando em maior eficácia das políticas públicas e das despesas governamentais (STIGLITZ, 2002).

O Quadro 2 informa sobre os documentos e os sítios eletrônicos consultados para avaliação da transparência das políticas de apoio aos produtores rurais objeto da pesquisa.

A atribuição de notas avaliou a "geração e disponibilização das informações", conferindo-se as categorias de 0 a 5 a cada quesito e política de apoio analisada, conforme descrito a seguir.
- (0) Não aplicável: utilizado quando o requisito de avaliação não foi cabível para aquele tipo de informação.

- (1) Informação não gerada ou não existente: casos em que a informação não foi localizada, mesmo mediante consultas aos órgãos responsáveis.

- (2) Informação produzida, mas apenas para propósitos internos e não disponivel para o público: casos em que as informações são mantidas sob sigilo, por alegações técnicas ou legais, não sendo disponibilizadas para o público.

- (3) Informação produ₹ida e disponivel para o público, mas somente mediante requerimento a órgão público: casos em que as informações existentes não são publicadas de maneira proativa, mas apenas mediante requerimento de informações.

\section{Quadro 2: Sítios eletrônicos e documentos analisados}

\begin{tabular}{|c|c|}
\hline $\begin{array}{l}\text { Requisitos de } \\
\text { Transparência }\end{array}$ & Sítios Eletrônicos e Documento Analisados \\
\hline $\begin{array}{l}\text { Previsão na lei } \\
\text { orçamentária anual }\end{array}$ & $\begin{array}{l}\text { Sistema Integrado de Administração Financeira (Siafi), } 2008 \text { a 2012, disponível no } \\
\text { sítio eletrônico: http://www2.camara.leg.br/atividade -legislativa/orcamentobrasil. }\end{array}$ \\
\hline $\begin{array}{l}\text { Existência de } \\
\text { descritor da ação } \\
\text { governamental }\end{array}$ & $\begin{array}{l}\text { Cadastros de Ações Orçamentárias, de } 2008 \text { a 2011, disponíveis no sítio eletrônico: } \\
\text { http://sidornet.planejamento.gov.br/docs/cadacao/; de 2012, no sítio eletrônico } \\
\text { https://gestao.orcamentofederal.gov.br/informacoes-orcamentarias/sistemas/docs/ } \\
\text { cadacao2012. }\end{array}$ \\
\hline $\begin{array}{l}\text { Acompanhamento } \\
\text { da execução da } \\
\text { despesa }\end{array}$ & $\begin{array}{l}\text { i) Anuário Estatístico do Banco Central, de } 2008 \text { a 2012, disponível no sítio eletrônico: } \\
\text { http://www.bcb.gov.br/?RELRURAL } \\
\text { ii) Siafi, de } 2008 \text { a } 2012 \text {, disponível no sítio eletrônico: }\end{array}$ \\
\hline $\begin{array}{l}\text { Levantamento de } \\
\text { séries históricas }\end{array}$ & $\begin{array}{l}\text { http://www2.camara.leg.br/atividade-legislativa/orcamentobrasil; e } \\
\text { iii) Sistema Eletrônico do Serviço de Informação ao Cidadão (e-SIC), disponível no } \\
\text { sítio eletrônico: http:/ / www.acessoainformacao.gov.br/. }\end{array}$ \\
\hline $\begin{array}{l}\text { Identificação dos } \\
\text { beneficiários }\end{array}$ & $\begin{array}{l}\text { i) Sítio eletrônico da Conab: www.conab.gov.br (Produtos e Serviços / Leilões } \\
\text { Públicos - para empresas que receberam bônus: Resultados por Adquirentes ou } \\
\text { Relação de Pagamentos / Adquirentes. Para produtores: Relação/Arrematante/ } \\
\text { Cooperativa/Produtor); e } \\
\text { ii) Sistema Eletrônico do Serviço de Informação ao Cidadão (e-SIC), disponível no } \\
\text { sítio eletrônico: http://www.acessoainformacao.gov.br/. }\end{array}$ \\
\hline $\begin{array}{l}\text { Aferição de } \\
\text { resultados e } \\
\text { cumprimento de } \\
\text { metas }\end{array}$ & $\begin{array}{l}\text { Relatórios de Avaliação dos Objetivos Setoriais e dos Programas do Plano Plurianual } \\
\text { 2008-2011, publicados entre } 2009 \text { e } 2012 \text { pelo Mapa e pelo MDA, disponíveis, } \\
\text { respectivamente, nos seguintes sítios eletrônicos: www.agricultura.gov.br e } \\
\text { www.mda.gov.br. }\end{array}$ \\
\hline
\end{tabular}

Fonte: Elaborado pelo autor. 
- (4) Informação produzida e disponivel para o público, mas de forma consolidada: casos em que as informações são publicadas de forma global, sem detalhamentos que permitam análises e comparações.

- (5) Informação produzida e disponibilizada ao público amplamente e de maneira detalhada: casos em que as informações são publicadas proativamente, sem necessidade de apresentação de requerimentos, sendo acessíveis e compreensíveis ao público em geral.
Após a avaliação de cada item, calculou-se a avaliação geral (média das avaliações individuais aferidas), transformando-a em percentual da nota máxima possível.

\section{Resultados e Discussão}

A Tabela 2 traz as avaliações de transparência dos principais instrumentos de apoio aos produtores rurais observadas na pesquisa:

Tabela 2: Avaliações de transparência dos principais instrumentos de políticas de apoio aos produtores rurais e respectivas fontes de recursos

\begin{tabular}{|c|c|c|c|c|c|c|c|c|}
\hline \multirow{4}{*}{$\begin{array}{l}\text { Requisitos de } \\
\text { Transparência }\end{array}$} & \multicolumn{8}{|c|}{ Políticas de Apoio aos Produtores Rurais e Respectivas Fontes de Recursos } \\
\hline & \multicolumn{4}{|c|}{ Crédito Rural } & \multicolumn{2}{|c|}{$\begin{array}{c}\text { Apoio à } \\
\text { Comercialização }\end{array}$} & \multicolumn{2}{|c|}{$\begin{array}{c}\text { Reescalonamento de Dívidas } \\
\text { Rurais* }\end{array}$} \\
\hline & Custeio & Investimentos & Investimentos & Pronaf & AGF & $\begin{array}{l}\text { Garantia e } \\
\text { Sustentação } \\
\text { de Preços }\end{array}$ & $\begin{array}{l}\text { Reescalonamento } \\
\text { de Dívidas Rurais }\end{array}$ & $\begin{array}{l}\text { Reescalonamento } \\
\text { de Dívidas Rurais }\end{array}$ \\
\hline & $\begin{array}{c}\text { Recursos } \\
\text { Obrigatórios }\end{array}$ & $\begin{array}{l}\text { BNDES/ } \\
\text { Finame }\end{array}$ & $\begin{array}{l}\text { Fundos } \\
\text { Constitucionais }\end{array}$ & $\begin{array}{l}\text { Poupança } \\
\text { Rural }\end{array}$ & $\begin{array}{l}\text { Tesouro } \\
\text { Nacional }\end{array}$ & $\begin{array}{l}\text { Tesouro } \\
\text { Nacional }\end{array}$ & $\begin{array}{l}\text { Subsídios } \\
\text { Explícitos }\end{array}$ & $\begin{array}{l}\text { Subsídios } \\
\text { Implícitos }\end{array}$ \\
\hline $\begin{array}{l}\text { Previsão na lei } \\
\text { orçamentária } \\
\text { anual }\end{array}$ & - & 1 & 3 & 3 & 3 & 3 & 3 & 1 \\
\hline $\begin{array}{l}\text { Existência de } \\
\text { descritor da } \\
\text { ação } \\
\text { governamental }\end{array}$ & 5 & 5 & 5 & 5 & 5 & 5 & 5 & 1 \\
\hline $\begin{array}{l}\text { Acompanha- } \\
\text { mento da } \\
\text { execução da } \\
\text { despesa }\end{array}$ & 3 & 3 & 3 & 3 & 3 & 3 & 3 & 3 \\
\hline $\begin{array}{l}\text { Levantamento } \\
\text { de séries } \\
\text { históricas }\end{array}$ & 3 & 3 & 3 & 3 & 5 & 5 & 3 & 3 \\
\hline $\begin{array}{l}\text { Identificação } \\
\text { dos beneficiários }\end{array}$ & 2 & 2 & 2 & 2 & 4 & 5 & 2 & 2 \\
\hline $\begin{array}{l}\text { Aferição de } \\
\text { resultados e } \\
\text { cumprimento } \\
\text { de Metas }\end{array}$ & 3 & 3 & 3 & 5 & 3 & 3 & 3 & 1 \\
\hline $\begin{array}{l}\text { Média de } \\
\text { Avaliação }\end{array}$ & 3,2 & 2,7 & 3,2 & 3,5 & 3,7 & 4,0 & 3,2 & 1,7 \\
\hline
\end{tabular}

Fonte: De Araujo (2012). 
A média dos resultados de avaliação constantes da Tabela 2 é 3,15, o que corresponde a $63 \%$ da avaliação máxima (5). Esse cálculo teve como principal propósito obter uma visão geral sobre o grau de transparência das informações sobre políticas de apoio aos produtores rurais.

O resultado é inferior à avaliação atribuída no Questionário de Orçamento Aberto, aplicado pela IBP em 2012, em que o Brasil atingiu 73\% dos pontos possíveis. Cabe ressaltar que a metodologia utilizada na avaliação da IBP apresenta as seguintes características que limitam a comparação: os quesitos de avaliação restringem-se à análise de transparência de documentos orçamentários e o conceito de disponibilidade da informação utilizado considera a pontuação máxima sempre que as informações sejam fornecidas pelos governos, ainda que isso dependa de requerimento.

Não foi objetivo desta pesquisa estabelecer comparação entre um índice geral de transparência do Governo Federal e uma avaliação específica das informações sobre políticas de apoio aos produtores rurais. O escopo da avaliação foi colher elementos para a discussão do modelo de prestação de informações governamentais, em face do referencial teórico de transparência pública.

Em função disso, considerou-se um universo de informações diferente daquele utilizado pela IBP, uma vez que os benefícios concedidos aos produtores rurais nem sempre transitam pelas leis orçamentárias. Esse procedimento é coerente com a metodologia de cálculo do PSE da OCDE, que tem escopo amplo, e capta todas as transferências financeiras relativas a esse segmento econômico específico, ainda que indiretas (OECD, 2010).
Adotou-se, ainda, uma visão de transparência que pressupõe uma postura proativa dos gestores públicos em disponibilizar informações de forma detalhada, acessível e compreensível. Esse conceito está em sintonia com as características da accountability descritas na literatura, e que devem ser adotadas por regimes democráticos que pretendem, de fato, estimular a participação da sociedade no controle das políticas implementadas pelo Estado (ACKerman, 2005; CARLos et al., 2008; JARDIM, 1999; MATIAS-PEREIRA, 2008).

Nesse contexto, considerou-se que uma média de $63 \%$ da avaliação máxima possível permite inferir que faltam às publicações do Governo Federal sobre políticas de apoio aos produtores rurais algumas características essenciais das práticas de accountability, como: proatividade, acessibilidade e incentivo à participação da sociedade (ACKERMAN, 2005; JARDIM, 1999; Matias-Pereira, 2008). Tal constatação aponta que os cidadãos têm tido seu papel limitado na formatação e avaliação das políticas direcionadas ao setor agropecuário, já que as informações relevantes sobre essa questão são publicadas apenas parcialmente e de maneira consolidada ou, em muitos casos, não são sequer divulgadas.

Tome-se aqui a avaliação da transparência das informações sobre os subsídios implícitos no reescalonamento de dívidas rurais. Verificou-se que nesse item se situaram as maiores dificuldades para obtenção de dados. Esse pode ser considerado exemplo de uma política hermética, sobre a qual a população pouco conhece em termos de objetivos, desembolsos, beneficiários e resultados obtidos.

Nas avaliações realizadas, também se verificou que a identificação dos beneficiários das políticas de apoio ao setor rural é uma informação praticamente 
indisponível. Essa política de informação dificulta o controle social, entendido como a participação do cidadão na gestão pública, na fiscalização, no monitoramento e no controle da administração pública. O controle social contribui para a gestão ao favorecer a boa e correta aplicação dos recursos e é um mecanismo de prevenção da corrupção que fortalece a cidadania (CGU, 2011). Um governo sem controle social desempenha funções reguladoras, extrativas e distributivas, atribui a si mesmo o controle do comportamento dos cidadãos, arrecada recursos e se considera independente para alocá-los, sem levar em conta critérios como igualdade, representação, participação e transparência (CAMPOS, 1990).

Na própria administração pública, contudo, é possível observar experiências exitosas em que o desejo de informar, aliado ao desenvolvimento da tecnologia da informação, permite que as entidades públicas ofereçam um expressivo conjunto de dados aos cidadãos interessados. Verificou-se que a Conab, por exemplo, disponibiliza informações detalhadas, na sua página eletrônica, sobre as principais políticas de comercialização. Naquele sítio eletrônico é possível identificar dados sobre as aquisições do Governo Federal e sobre outros instrumentos utilizados para garantia e sustentação de preços dos produtos agropecuários.

A estratégia de disponibilização de informações adotada pela Conab é coerente com a diretriz expressa na Lei $\mathrm{n}^{2}$ 12.527, de 18 de novembro de 2011 (Lei de Acesso à Informação), segundo a qual o Governo Federal deve utilizar a internet como meio privilegiado de divulgação de dados (BrasiL, 2011).

Cumpre ressaltar, porém, que a utilização da internet como principal canal de comunicação é vista como grande potencial, mas também como enorme desafio como instrumento de transparência pública. Diversos autores levantam questionamentos sobre a capacidade de os cidadãos processarem a infinidade de informações disponibilizadas (DA SILVA,

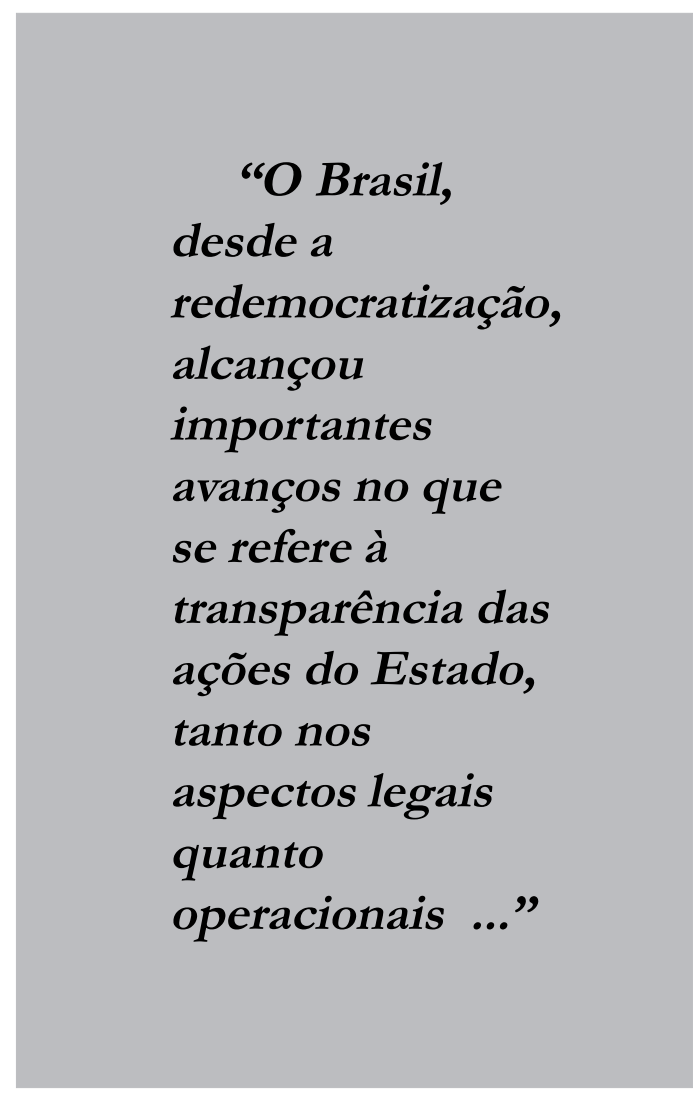

2009; Torres, 2004; Matias-Pereira, 2010; JARDIM, 1999).

A comunicação política do Estado por meio do ambiente digital não implica o alcance de toda a esfera civil, ou a captação da atenção do cidadão por todo o tempo, pelo fato de haver um portal em atividade na rede. Seria preciso consolidar os sítios oficiais como fonte de informação pública e comunicação cidadã, tornando essas fontes de dados atraentes ao público em geral (DA Silva, 2009). No Brasil, não 
obstante os avanços ocorridos desde o processo de democratização ocorrido nos anos 1980, com a instalação de sistemas de informações e ampla disponibilidade de dados na internet, há ainda carência de clareza e integração entre os dados, o que torna praticamente inviável o acesso do cidadão comum aos mesmos (TORRES, 2004).

Portanto, a simples disponibilização de dados, sem uma política clara de comunicação e gestão da informação, não contribui para a plena implantação da accountability no processo de difusão de informações. Como podemos constatar, o problema é complexo e de difícil equacionamento, uma vez que a informação, mesmo que esteja disponível, nem sempre garante que o controle social será exercido pelo cidadão, objetivo primordial desse esforço de transparência empreendido pela administração pública brasileira (TORRES, 2004).

No caso das políticas de apoio aos produtores rurais, a análise realizada nesta pesquisa indica que, a despeito da boa disponibilidade de dados, o controle social desses benefícios pode não estar sendo exercido, em sua plenitude, em função do conhecimento limitado da população sobre as principais políticas, o montante de recursos efetivamente alocado, as fontes utilizadas e os grupos beneficiados.

No sentido de dar maior transparência a essas políticas de apoio, o Governo Federal poderia adotar os seguintes aperfeiçoamentos:

- disponibilização de todas as informações relevantes para o controle social no maior número de mídias possível (OECD, 2002);

- oferta proativa de dados, sem necessidade de solicitações pelos interessados (ACKerman, 2005; Jardim, 1999; MatiasPereira, 2008);

- integração e padronização de bancos de dados (Torres, 2004);
- melhoria dos instrumentos de avaliação dos resultados das políticas públicas (STiglitz, 2002); e

- aprimoramento da inteligibilidade das informações (Jardim, 1999; Matias-Pereira, 2002; TORRES, 2004).

\section{Conclusões}

O Brasil, desde a redemocratização, alcançou importantes avanços no que se refere à transparência das ações do Estado, tanto nos aspectos legais quanto operacionais (Torres, 2004). Nesse período, ampliou-se em quantidade e qualidade o conjunto de informações disponibilizadas para que a população tenha condições de exercer o controle social. No ranking internacional da transparência, em pesquisa conduzida pela Parceira Internacional de Orçamento (International Budget PatnershipIBP) em 2012, o Brasil alcançou o $12^{\circ}$ lugar entre 100 países pesquisados, obtendo $73 \%$ dos pontos possíveis, denotando abertura orçamentária acima da média.

No presente trabalho, que utilizou metodologia elaborada com base no Questionário de Orçamento Aberto desenvolvido pela IBP, a transparência média das informações sobre políticas de apoio aos produtores rurais foi de $63 \%$ da avaliação máxima. Os resultados não são comparáveis, pois decorrem de metodologias e universos de abrangência distintos, mas contribuem para a discussão do modelo de prestação de informações governamentais em face do referencial teórico de transparência pública.

Verificou-se, na pesquisa realizada, que há uma significativa quantidade de dados à disposição dos cidadãos, mas com um nível de detalhamento e apresentação que pode ser considerado insatisfatório para garantir o efetivo controle social das 
ações governamentais. As avaliações realizadas mostraram que os principais instrumentos de política agrícola e as respectivas fontes de recursos não dispõem de uma política unificada de divulgação de informações. Desse modo, observouse que dados importantes deixam de ser disponibilizados ou são publicados de maneira dispersa e pouco intuitiva para o cidadão.

Diante dos problemas apontados, o atingimento de um nível de transparência, na divulgação de informações relacionadas às políticas de apoio aos produtores rurais no âmbito do Governo Federal, depende de alguns aprimoramentos para que possa ser considerado accountable. As principais medidas devem ser direcionadas à melhoria na proatividade de disponibilização das informações, à clareza dos dados, à integração dos diversos canais e à avaliação dos resultados.

(Artigo recebido em junho de 2013. Versão final em dezembro de 2013).

\section{Referências bibliográficas}

ACKerman, J. Social accountability in the public sector: a conceptual discussion. Washington: World Bank, 2005.

AvritZer, L. Sociedade civil, instituições participativas e representação: da autorização à legitimidade da ação. Revista de Ciências Sociais, v. 50, nº 3, p. 443 a 464, 2007.

Brasil. Lei $\mathrm{n}^{\circ}$ 12.527, de 18 de novembro de 2011. Regula o acesso a informações previsto no inciso XXXIII do art. $5^{\circ}$, no inciso II do $\ 3^{\circ}$ do art. 37 e no $\int 2^{\circ}$ do art. 216 da Constituição Federal; altera a Lei no 8.112, de 11 de dezembro de 1990; revoga a Lei $\mathrm{n}^{\mathrm{o}}$ 11.111, de 5 de maio de 2005, e dispositivos da Lei no 8.159, de 8 de janeiro de 1991; e dá outras providências. Diário Oficial da União, Brasília.

Campos, A. M. Accountability: quando poderemos traduzi-la para o português? Revista de Administração Pública, Rio de Janeiro, FGV, v.24, n. 2, fev/abr. de 1990.

CARlos, F.A et. al. Uma discussão sobre a criação de indicadores de transparência na gestão pública federal como suporte ao ciclo da política pública. Revista de Contabilidade do Mestrado em Ciências Contábeis da UERJ, Rio de Janeiro, v.13, n.2, p.12, maio/ago. de 2008.

CGu, Controladoria-Geral da União. Acesso à informação pública: uma introdução à Lei no 12.527, de 18 de novembro de 2001. Brasília, 2011.

Da SiLVA, S. P. Democracia online: pressupostos teóricos e inovações estruturais na comunicação do Estado contemporâneo. Artigo apresentado no III Congresso DA Associação Brasileira de Pesquisadores em Comunicação e Política (Compolítica). São Paulo: PUC, 2009.

De Araujo, W. P. Transparência na gestão pública: as políticas de apoio ao produtor rural. 2012.. Dissertação de Mestrado - Faculdade de Agronomia e Medicina Veterinária, Universidade de Brasília, Brasília. 
FilgueIras, F. Sociedade civil e accountability societal no controle da corrupção no Brasil. Em Debate, Belo Horizonte, v.3, n.4, p.14-28, dez. 2011.

ForTis, M. F. A. Transparencia y control social en el Gobierno Federal Brasileño: análisis de los principales avances y desafíos en el período post-LRF. Revista Internacional de Presupuesto Público - ASIP, Año XXXVI, nº 68, Noviembre/Diciembre de 2008.

Gasques, J. G.; Villa Verde, C.M; Bastos, E. T. Gastospúblicos em agricultura: retrospectiva e prioridades. Brasília: Ministério da Agricultura, Pecuária e Abastecimento, 2006.

IвP, International Budget Partnership. OBI - Metodology 2010. Washington, 2011. Pesquisa do orçamento aberto 2012. Washington, 2012.

Jardim, J. M. Transparência e opacidade do Estado no Brasil: usos e desusos da informação governamental. Rio de Janeiro: EdUFF, 1999.

Lavalle, A. G. Sociedade civil, representação e a dupla face da accountability: Cidade do México e São Paulo. Caderno CRH, Salvador, v. 21, n. 52, p. 67-86, Jan./Abr. de 2008.

Lavalle, A. G.; Vera, E. I. A trama da crítica democrática: da participação à representação e à accountability. Lua Nova: Revista de Cultura e Política, São Paulo, v. 84, p. 353-364, 2011.

Matias-Pereira, J. Reforma do Estado e transparência: estratégias de controle da corrupção no Brasil. VII Congreso Internacional del CLAD sobre la Reforma del Estado y de la Administración Pública. Lisboa, 2002.

Reforma do Estado e controle da corrupção no Brasil. Caderno de Pesquisas em Administração, São Paulo, v. 12, n. 2, p. 1-17, abril/junho de 2005.

. Curso de Administração Pública: foco nas instituições e ações governamentais. São Paulo: Atlas, 2008.

Governança no setor público. São Paulo: Atlas, 2010.

OCDE, Organização para cooperação e desenvolvimento econômico. Análise das políticas agrícolas: Brasil. Paris, 2005.

OECD, Organization for Economic Co-operation and Development. OECD best practices for budget transparency. Paris, 2002.

OECD'S producer support estimate and related indicators of agricultural support (the PSE manual). Paris, 2010.

Ramos, L. E. R. Estimativa dos custos fiscais da subvenção econômica à agropecuária. 2011. Dissertação (mestrado) - Universidade de Brasília - Departamento de Economia.

SAnches, O. M. Dicionário de orçamento, planejamento e áreas afins. $2^{a}$ Edição. Brasília: Prisma/ OMS, 2004.

STIGLITZ, J. Transparency in Government. In: The right to tell - the role of mass media in economic development. Washington, DC: The World Bank, 2002.

Torres, M. D. F. Estado, democracia e Administração Pública no Brasil. Rio de Janeiro: Editora FGV, 2004. 


\section{Resumo - Resumen - Abstract}

\section{Avaliação da transparência das informações sobre políticas de apoio aos produtores rurais no Brasil \\ Wellington Pinheiro de Araujo e Mauro Eduardo Del Grossi}

A transparência das ações do Estado é fundamental para a democracia e o desenvolvimento econômico. Este artigo teve como objetivo avaliar o grau de transparência das informações sobre políticas de apoio aos produtores rurais no Brasil. Foram selecionadas para análise as políticas do Governo Federal que contribuíram com as maiores transferências financeiras para o setor agropecuário nos últimos anos. O Questionário de Orçamento Aberto da International Budget Partnership (IBP) foi utilizado como referência metodológica. Os resultados obtidos apontam que a transparência dos principais instrumentos de política agrícola, utilizados atualmente no Brasil, situa-se em 63\% da avaliação máxima possível, enquanto que o índice de transparência orçamentária do governo brasileiro, calculado pela IBP em 2012, ficou em 73\%. Os resultados não são diretamente comparáveis, pois decorrem de metodologias e universos de abrangência distintos, mas contribuem para a discussão do modelo de prestação de informações governamentais em face do referencial teórico de transparência pública.

Palavras-chave: accountability; políticas de apoio ao produtor rural; transparência governamental

Evaluación de la transparencia de las informaciones sobre políticas de apoyo a los productores rurales en Brasil

Wellington Pinheiro de Araujo y Mauro Eduardo Del Grossi

La transparencia de las acciones del gobierno es fundamental para la democracia y el desarrollo económico. Este estudio tuvo como objetivo evaluar el grado de transparencia de la información sobre las políticas de apoyo a los agricultores en Brasil. Se seleccionaron para análisis las políticas del Gobierno Federal que contribuyeron con las mayores transferencias financieras al sector agrícola en los últimos años. El Cuestionario de Presupuesto Abierto de la International Budget Partnership (IBP) se utilizó como marco metodológico. Los resultados indican que la transparencia de los principales instrumentos de política utilizados en la actualidad en Brasil se sitúa en el 63\% de la máxima calificación posible, mientras que el índice de transparencia presupuestaria del gobierno brasileño, calculado por el IBP en 2012, se situó en el 73\%. Los resultados no son directamente comparables, ya que provienen de metodologías y universos de espectros diferentes, pero contribuyen para la discusión del modelo que proporciona informaciones del gobierno en relación con el marco teórico de la transparencia pública.

Palabras clave: responsabilidad; políticas de apoyo a los agricultores; transparencia gubernamental

\section{Measuring the degree of information transparency of policies to support farmers in Brazil \\ Wellington Pinheiro de Araujo and Mauro Eduardo Del Grossi}

The transparency of state actions is essential for democracy and economic development. This study aimed to measure the degree of information transparency of policies to support farmers in Brazil. Federal Government policies, which contributed to the largest financial transfers to the Brazilian agricultural sector in recent years, were selected for analysis. The Open Budget Questionnaire of the International Budget Partnership (IBP) was used as a reference to build 
the methodology applied to this work. The results indicate that the transparency of the main farm policy instruments currently used in Brazil stands at 63\% of the maximum rating possible, while the Brazilian government budget transparency index, calculated by IBP in 2012, was $73 \%$. The results are not directly comparable because they derive from different methodologies, but contribute to the discussion of transparency and public information access.

Keywords: accountability; policies to support farmers; government transparency

Wellington Pinheiro de Araujo é mestre em Agronegócios pela Universidade de Brasília (UnB) e especialista em Políticas Públicas pela Universidade Federal do Rio de Janeiro (UFRJ). Atua como consultor de Orçamento e Fiscalização Financeira da Câmara dos Deputados. Contato: wellington.araujo@camara.leg.br

Mauro Eduardo Del Grossi é doutor em Ciência Econômica pela Universidade Estadual de Campinas (Unicamp) e professor da Universidade de Brasília (UnB), campus de Planaltina, e integrante do Programa de Pós-Graduação em Agronegócios (Propaga). Contato: delgrossi@unb.br 